\title{
Role of MK2 signaling pathway mediating microglia/macrophages polarization in chronic compression injury of cervical spinal cord
}

\author{
Lei Yu, Hongxing Song, Xiutong Fang, Yali Hu \\ Department of Spine Surgery, Beijing Shijitan Hospital, Capital Medical University, Beijing, China \\ Contributions: (I) Conception and design: L Yu, H Song; (II) Administrative support: H Song; (III) Provision of study materials or patients: All \\ authors; (IV) Collection and assembly of data: All authors; (V) Data analysis and interpretation: L Yu; (VI) Manuscript writing: All authors; (VII) \\ Final approval of manuscript: All authors. \\ Correspondence to: Hongxing Song. Department of Spine Surgery, Beijing Shijitan Hospital, Capital Medical University, The Ninth Clinical Medical \\ College of Peking University, No. 10 Tieyi Road, Beijing 100038, China. Email: songhx0312@163.com.
}

\begin{abstract}
Background The role of inflammatory factors in the chronic compression injury of cervical spinal cord has drawn more attention recently, however, the mechanism of which is still unclear. In this study, microglia/ macrophages polarization in the inflammatory responses to the injury and its regulation by MK2 signaling pathway have been investigated.
\end{abstract}

Methods: twy/twy mice at the age of 6-24 weeks were used in the animal model for the chronic compression of cervical spinal cord. ICR (Institute of Cancer Research) mice were used as the control group. MK2 inhibitor (PF-3644022, $30 \mathrm{mg} / \mathrm{kg}$ ) was administrated intragastrically to twy/twy mice from weeks 20 to 24. The compression of cervical spinal cord was identified by CT/MRI. The cervical spinal cord between C2 and C3 of vertebral segments were investigated by Western blot and Real-time PCR. The animal behaviors were evaluated by BMS score.

Results: Western blot and Real-time PCR showed that the expressions of iNOS and Arg-1 in the compressed spinal cord of twy/twy mice were significantly higher than those of the control group. After treatment with PF-3644022, the expression of Arg1 was increased while that of iNOS decreased. Realtime PCR revealed the increased expressions of inflammation related factors (such as IL-1 $\beta, N F-\kappa B$, TNF- $\alpha$, MK2) and pro-apoptotic gene (Bax) except the decreased expression of anti-apoptotic gene (Bcl-2). Nevertheless, such increases were vanished after treatment of PF-3644022 except an increased expression of Bcl-2. The BMS score showed a reduced motor function of the twy/twy mice. The motor function was enhanced again with the treatment of PF-3644022.

Conclusions: Microglia/macrophages polarization may be involved in the inflammatory response to the chronic compression of cervical spinal cord. It can be regulated by the MK2 signaling pathway. Therefore, it is possible to relieve the chronic compression of cervical spinal cord by regulating microglia/macrophages polarization through MK2 signaling pathway.

Keywords: Spinal cord; chronic compression; MK2: spinal cord injury; microglia/macrophages; polarization

Submitted Feb 12, 2020. Accepted for publication Aug 19, 2020.

doi: 10.21037/apm-20-396

View this article at: http://dx.doi.org/10.21037/apm-20-396

\section{Introduction}

Chronic compression of cervical spinal cord is a common disease in spinal surgery. It causes motor weakness, sensory loss of limbs, bowel and bladder dysfunction, and seriously affects the quality of life and work ability (1).
The chronic compression of cervical spinal cord might be incurred by the following factors, for instance, spondylosis, disk degeneration, the ossification of the posterior longitudinal ligament or ligamentum flavum, congenital stenosis, and spinal tuberculosis or tumors. Moreover, neck 
movements are regarded as additional causes, specifically physiological narrowing of canal diameter caused by neck extensions and the stretch imposed on spinal cord by physiological neck movements. However, up to now the molecular mechanism of the chronic compression has not been clarified. In the previous investigations, inflammation has been considered as an important pathological factor $(2,3)$. Microglia is macrophage in the central nervous system. It works as an important cell in the inflammatory process of the compression injury in the spinal cord. Autopsy studies showed that inflammatory reactions were activated by microglia/macrophages in the cervical spinal cord specimens of patients with cervical spondylotic myelopathy $(4,5)$ Our previous studies revealed that MK2 signaling pathway was involved in the inflammation of the chronic compression inducing cervical spinal cord injury (2). However, the details in how MK2 signaling pathway could influence microglial cell polarization in the chronic compression are still unclear.

We present the following article in accordance with the ARRIVE Reporting Checklist (available at http://dx.doi. org/10.21037/apm-20-396).

\section{Methods}

\section{Animals}

Tip-toe Walking Yoshimura (twy/twy) mouse aged 6 weeks were purchased from the Experimental Animal Center (Kanagawa, Japan). These mice inherited an autosomal recessive mutation, and exhibited spontaneous calcified deposits posteriorly at the $\mathrm{C} 2-\mathrm{C} 3$ vertebral level, producing various degrees of compression at the spinal cord between $\mathrm{C} 2$ and $\mathrm{C} 3$ segments. For this reason, the twy/twy mouse is suitable to investigate the chronic compression of the cervical spinal cord $(2,6,7)$. The mice were housed in a specific pathogen-free (SPF) environment at the Animal Laboratory of Xuanwu Hospital, Capital Medical University. Experiments were performed under a project license (No. XWH201905001) granted by institutional ethics committee of Xuanwu Hospital, Capital Medical University, in compliance with Xuanwu Hospital, Capital Medical University institutional guidelines for the care and use of animals.

PF-3644022 hydrate is a potent inhibitor of mitogenactivated protein kinase 2 signaling pathway (MK2 signaling pathway). The twy/twy mice aged 20 weeks were intragastrically treated with $30 \mathrm{mg} / \mathrm{kg}$ PF-3644022 once daily for 4 weeks. twy/twy mice without the drug injection were used as the control animals in the animal model. The
Institute of Cancer Research (ICR) mice matched the age and without any treatments were used as the reference of the controls. The mice were killed by ether anesthesia at the age of 24 weeks. The segment of the compressive lesion was removed (8). The whole protocol of the investigations was approved by the Ethical Committee for Animal Research at Capital Medical University.

\section{Micro-computer tomography (CT) analysis}

The cervical spine of mice was examined by micro-CT (R_mCT2: Inveon Research Workplace 4.2 produced by Siemens, owned by the Experimental Center of Capital Medical University) at 39-um isotropic resolution. mice were taken prone position after ether anesthesia to perform sagittal and coronal examinations. The ossification of the posterior longitudinal ligament and the compression of the spinal cord were examined.

\section{Magnetic resonance imaging (MRI)}

The cervical spine of mice was examined by MRI (Tesla MRI magnet: PharmaScan 70/16 USIn-vivo MR Imaging System produced by Bruker, Germany, owned by the Experimental Center of Capital Medical University). The manifestation of spinal cord compression was investigated. Mice were taken prone position after ether anesthesia to examine the T2-weighted axial and sagittal sites. The parameters used in the MRI are the followings: $\mathrm{TE}=92 \mathrm{~ms}$, TR $=3,620 \mathrm{~ms}$, layer thickness $2 \mathrm{~mm}, \mathrm{FOV}=80 \mathrm{~mm}$. The ossification of the posterior longitudinal ligament and the compression of the spinal cord were examined.

\section{Behavioral observation}

Basso Mouse Scale (BMS) is based on a systematic, indepth analysis of locomotor recovery from SCI specifically in mice. After given the PF-3644022, the scores were evaluated independently by three experienced technicians. The average value of the two data sets was used for the statistical analysis (9).

\section{Western blot analysis}

Spinal cord tissues from C2 to C3 were collected at a given time after surgery. The tissues treated with or without $\mathrm{vx}-$ 765 were homogenized with a buffer containing $50 \mathrm{mM}$ Tris (pH 6.8), 2\% SDS, $20 \%$ glycerol, $100 \mu M$ PMSF, protease 
inhibitor mixture (Promega), and HALT ${ }^{\mathrm{TM}}$ phosphatase inhibitor cocktail (Thermo Scientific). The supernatants were collected after centrifugation at $12,000 \mathrm{~g}$ for $10 \mathrm{~min}$ and at $4{ }^{\circ} \mathrm{C}$. The protein concentration was determined using a BCA protein assay (QuantiPro BCA Assay Kit, Sigma-Aldrich) according to the manufacturer's instructions. Protein samples were separated by SDS-polyacrylamide gel electrophoresis, and transfer onto poly-vinylidene fluoride (PVDF) membranes (Millipore Corporation, USA). The membranes were blocked with $5 \%$ skimmed milk for $1 \mathrm{~h}$ at room temperature, and then incubated at $4{ }^{\circ} \mathrm{C}$ for one night with the primary antibodies including rabbit anti-Arg-1 (1:1,000; Cell Signaling Technology); rabbit anti-iNOS $(1: 1,000$; Abcam); anti-MK2 (1:500; Abcam), After three washes, the membranes were incubated with an HRP-coupled secondary antibody at room temperature for $1 \mathrm{~h}$, and washed three times again for 10 min each at room temperature. Finally, all the membranes were imaged using densitometry (Bio-Rad, Hercules, CA, USA) and quantified with the densitometric analysis (Image J software, NIH) $(10,11)$.

\section{Realtime PCR analysis}

Total RNA was isolated from the primary cultured microglia using the TRIzol (Invitrogen, Carlsbad, CA, USA) reagent according to the manufacturer's instructions. The nucleic acid purity was quantified and analyzed using the Nano Drop 2000 spectrophotometer (Thermo Scientific, Bremen, Germany). The RNA was reverse-transcribed to cDNA using TransScript One-Step gDNA Removal and cDNA Synthesis SuperMix kit (TransGen Biotech, Beijing, China). GAPDH was used as an internal control to normalize the expression level. qPCR was conducted in a CFX $96^{\mathrm{TM}}$ real-time system employing the $\mathrm{S}$ so Advanced ${ }^{\mathrm{TM}}$ Universal SYBR. Green Supermix was employed for the cDNA quantification. The primers used were listed in the following:

Arg-1 (Forward-TTGGGAAGACAGCAGAGGAG-3, Reverse-GTCAGTCCCTGGCTTATGGT),

iNOS (Forward-CATGACTCCCAGCACAAAGG, Reverse-CTGGAACAGCACTCTCTTGC),

MK2 (Forward-TTTCCTAACCCGGAGTGGTC, Reverse-CCATCGTTCCTTGTCCTCCT),

TNF-a (Forward-TCTCTTCAAGGGACAAGGCT, Reverse-GGCAGAGAGGAGGTTGACTT),

Bax (Forward-CAAGAAGCTGAGCGAGTGTC, Reverse-GTCCACGTCAGCAATCATCC),

Bcl-2 (Forward-GCATGCGACCTCTGTTTGAT,
Reverse-CAGGTATGCACCCAGAGTGA), IL-1 (Forward-AAGAGCCCATCCTCTGTGAC, Reverse-AGCTCATATGGGTCCGACAG), NF-KB (Forward-GACCCAGGAGTGTTCACAGA, Reverse-CTCAGCTGTGGAGTGAGACA), GAPDH (Forward-TGCCCCCATGTTTGTGATG, Reverse-TGTGGTCATGAGCCCTTCC) $(10,11)$.

\section{Statistical analysis}

Analysis of variance (ANOVA) followed by Scheffe or Tukey's test was carried out with the Statistical Package for the Social Sciences software (SPSS 17.0 Statistical Software). The measured data were denoted as mean \pm standard deviation. $\mathrm{P} \leq 0.05$ was considered as the statistical difference.

\section{Result}

\section{Micro-CT}

Sagittal and axial view respectively showed the spontaneous ossification protruded into the spinal cord (Figure 1A,B).

\section{MRI scanning}

Figure 1C,D displayed the representative T2-weighted sagittal and axial MR images of twy/twy mice. The cervical ossification and spinal cord compression were identified at C2-C3.

\section{Bebavioral test}

BMS score was analyzed in ICR mice and twy/twy mice (Figure 2). After PF-3644022 treatment for 4 weeks, results showed that motor function was significantly decreased in the in twy/twy mice as compared to ICR mice $(\mathrm{P}<0.01)$, but the motor function was significantly improved in the in twy/twy mice given PF-3644022 as compared to twy/twy mice $(\mathrm{P}<0.05)$. This suggests that the inhibition of MK2 inhibitor is able to improve the outcome and prevent the deterioration of neurological dysfunction of twy/twy mice.

\section{Western blot assay for MK2 and M1/M2 phenotypic marker}

Western blot assay showed the MK2 expressions in Figure $3 \mathrm{~A}$. The expression was increased significantly in twy/twy mic e as compared to ICR ones. MK2 inhibitor down-regulated the MK2 expression in twy/twy mice. 

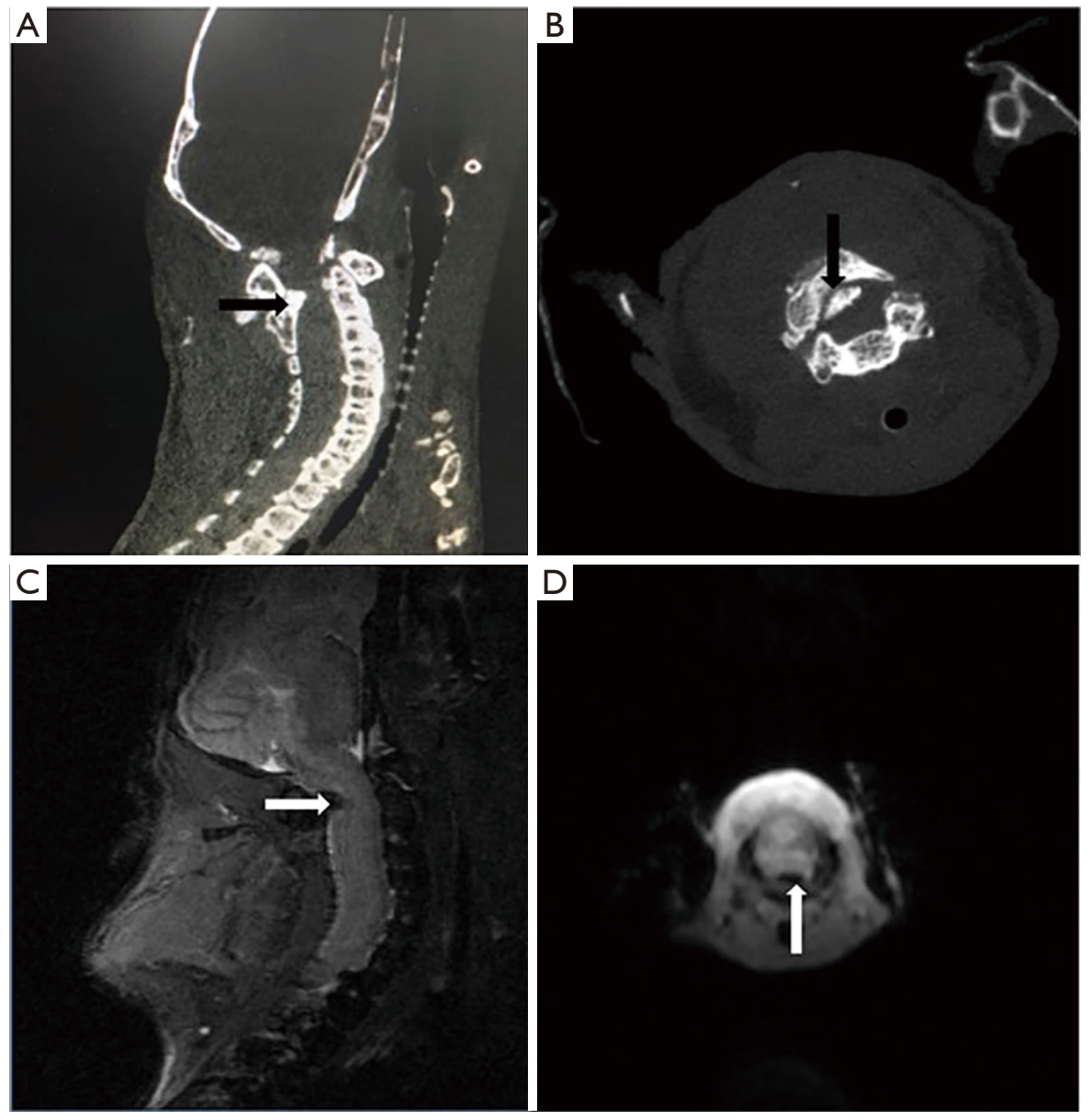

Figure $1(A, B)$ Shows the cervical spine in the sagittal and axial view respectively in the micro-computer tomography (CT). Spontaneous ossification protruded into the spinal cord, as the arrow indicated. It exerted compression on the spinal cord. This can be seen again in the magnetic resonance imaging in (C,D), sagittal and axial view respectively. The arrows indicate spontaneous ossification.

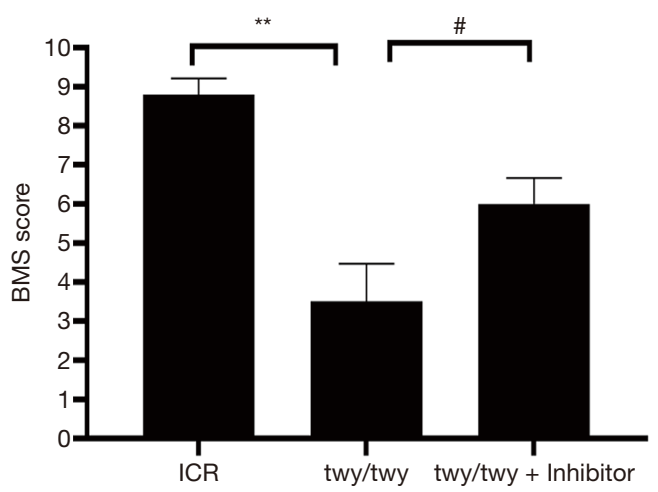

Figure 2 Inhibition of MK2 signaling pathway improves the motor function of twy/twy mice. Data are expressed as means \pm SD. $n=10$ in each group. **, $\mathrm{P}<0.01$ for between ICR and twy/twy group. *, $\mathrm{P}<0.05$; for between twy/twy+inhibitor group and twy/twy group. ICR, Institute of Cancer Research.
The expression of Arg-1 characterized as M2 markers was increased in twy/twy mice as compared to ICR mice (Figure 3B). MK2 inhibitor PF-3644022 up-regulated the Arg-1 expression in twy/twy mice. Meanwhile. The iNOS expression that is employed as the marker of M1 polarization. The iNOS expression was notably increased in twy/twy mice with the chronic compression of spinal cord as compared to ICR mice. However, MK2 inhibitor PF3644022 down-regulated the iNOS expression in twy/twy mice (Figure 3C). Western blot assay of MK2, Arg-1 and iNOS expression (Figure 3D).

\section{Realtime PCR analysis for the M1/M2 phenotypic marker}

As shown in Figure 4A,B, the relative Arg-1 mRNA level, one marker of M2 polarization, was increased in the twy/ 

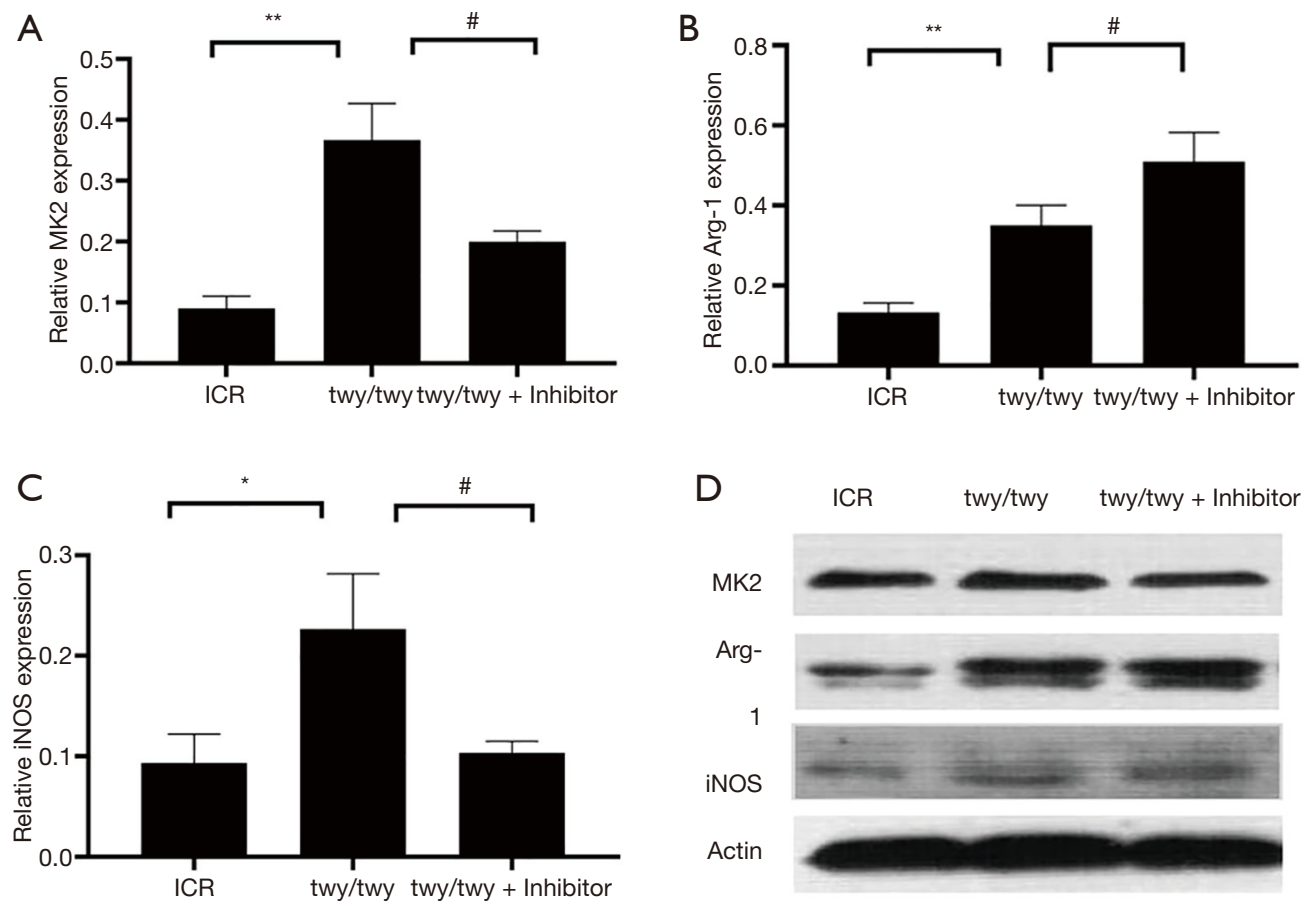

Figure 3 Effects of PF-3644022 (a MK2 inhibitor) on the MK2 expression and microglia/macrophages polarization. The quantification of MK2 expression and the markers related to microglia/macrophages polarization were determined by Western blot (A,B,C,D) Data are presented as mean $\pm \mathrm{SD} . \mathrm{n}=3$ in each group. * $\mathrm{P}<0.05$; **, $\mathrm{P}<0.01$ for between ICR and twy/twy group. * $\mathrm{P}<0.05$ for between twy/ twy+inhibitor group and twy/twy group. ICR, Institute of Cancer Research.
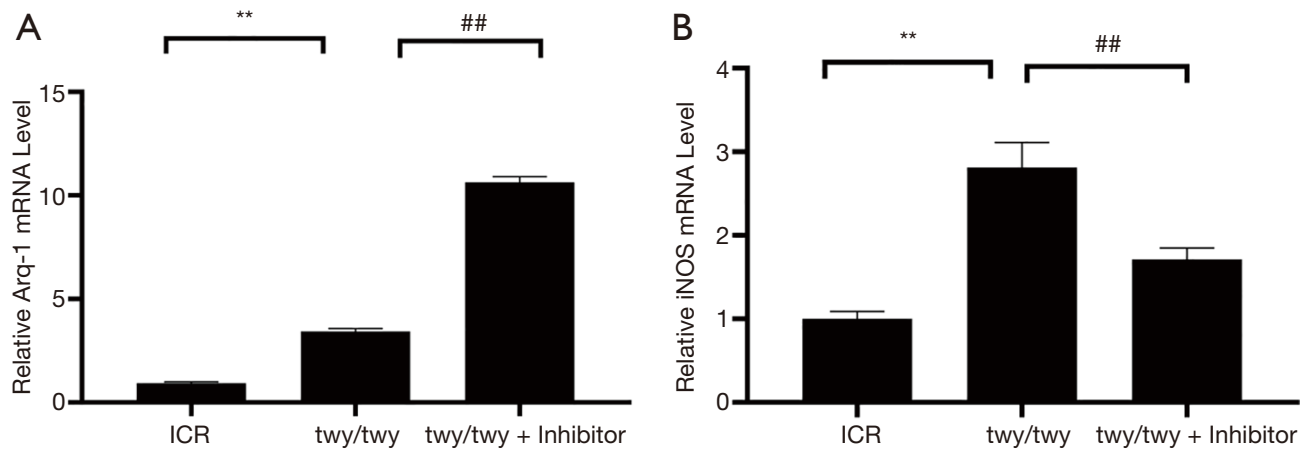

Figure 4 Effects of PF-3644022 (a MK2 inhibitor) on the microglia/macrophages polarization. The markers related to microglia/ macrophages polarization were determined by real-time PCR $(\mathrm{A}, \mathrm{B})$. Data are presented as mean \pm SD. $\mathrm{n}=3$ in each group. ** $\mathrm{P}<0.01$ for between ICR and twy/twy group; ${ }^{\# \#}, \mathrm{P}<0.01$ for between twy/twy+inhibitor group and twy/twy group.

twy mice as compared to ICR mice. MK2 inhibitor PF3644022 up-regulated further the expression level of the Arg-1 mRNA in twy/twy mice. The iNOS expression, one marker of M1 polarization, was increased in twy/twy mice as compared to ICR mice. MK2 inhibitor PF-3644022 however reduced the iNOS level in twy/twy mice.

\section{The real-time PCR analysis for the inflammatory cytokines}

As is shown in Figure 5, the TNF- $\alpha$ expression was increased in twy/twy mice as compared to ICR mice. MK2 inhibitor PF3644022 down-regulated the TNF- $\alpha$ expression. The similar results can be seen for the IL-1 NF-kB and MK2 mRNA. 

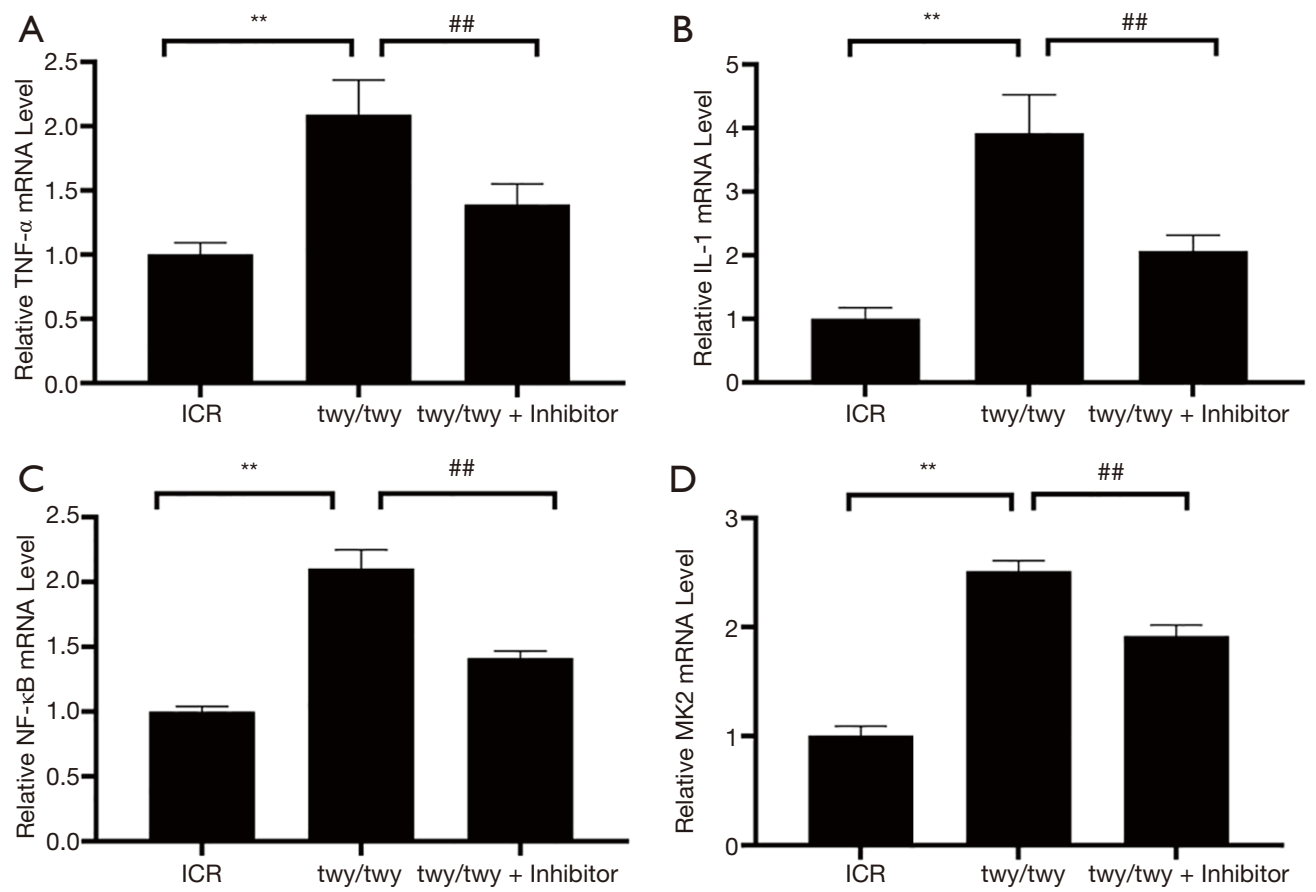

Figure 5 Effects of PF-3644022 (a MK2 inhibitor) on the production of inflammatory cytokines. The mRNA expression level of inflammatory cytokines were determined by Realtime PCR. Data are presented as mean $\pm \mathrm{SD} . \mathrm{n}=4$ in each group. **, $\mathrm{P}<0.01 \mathrm{for}$ between ICR and twy/twy group; ${ }^{\#}, \mathrm{P}<0.01$ for between twy/twy+inhibitor group and twy/twy group.
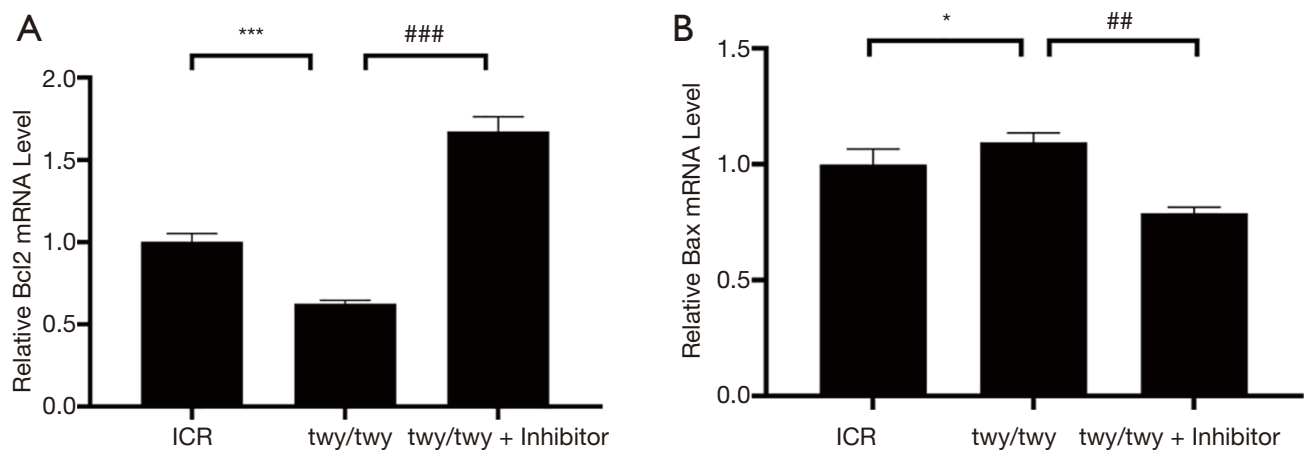

Figure 6 Effects of PF-3644022 (a MK2 inhibitor) on the production apoptosis related genes. The mRNA expression level of apoptosis related genes were determined by Realtime PCR. Data are presented as mean \pm SD. $n=4$ in each group *, $\mathrm{P}<0.05$; ***, $\mathrm{P}<0.001$ for between ICR and twy/twy group. ${ }^{\#}, \mathrm{P}<0.01$ and ${ }^{\# \# \#,} \mathrm{P}<0.001$ for between twy/twy+inhibitor group and twy/twy group.

\section{The Realtime PCR analysis for the apoptosis related genes}

As is shown in Figure 6, Bax expressions were increased in twy/twy mice as compared to ICR mice. Bcl-2 expressions were decreased in twy/twy mice as compared to ICR mice. Bax promotes apoptosis, while Bcl-2 antagonizes Bax. Following giving the PF-36440224 inhibitor, the Bax expression was down-regulated while the Bcl-2 up-regulated.

\section{Discussion}

Microglia/macrophage polarization is involved in the inflammatory response of the chronic compression injury of cervical spinal cord

Mechanical compression is the main cause of chronic compression injury in cervical spinal cord (3). However, 
the mechanical compression alone cannot account for all clinical manifestations. The literature showed that inflammatory factors played an increasingly important role in the pathogenesis of the injury (12). Microglia are critical nervous immune cells that maintain the neural environment and response to injury and repair. Microglia are the major mediators of neuroinflammation too. Their functions and characteristics are quite similar to those of macrophages $(13,14)$. The activated microglia have two phenotypes: classical M1 and the alternative M2 phenotypes. M1 microglia are proinflammatory that accelerates neuronal death and central nervous system tissue damages. These cells produce pro-inflammatory cytokines (TNF- $\alpha$, IL-1 $\beta$, IL-12) and express a high level of iNOS. In a contrast, M2 microglia produce anti-inflammatory mediators, such as interleukin-10 (IL-10) and transforming growth factor- $\beta$ (TGF- $\beta$ ). They express a high level of Arg-1, and deactivate pro-inflammatory cell phenotypes and re-establish homeostasis. However, the microglial/ macrophage polarization in the chronic compression inflammation of cervical spinal cord was reported rarely $(15,16)$, and needed further confirmation.

In the present work, the animal model was established by using twy/twy mice. Western blot and Real-time PCR showed that M1 and M2 cells expression level in twy/twy mice were increased as compared to those in ICR mice, suggesting that the microglia/macrophages polarization took place in the compressed cervical spinal cord. Realtime PCR showed the increases in the inflammatory factors TNF- $\alpha, N F-\kappa B, I L-1 \beta$ and in the pre-apoptosis gene Bax and the decreased in the anti-apoptosis gene Bcl-2 in twy/twy mice as compared to the ICR mice. The motor function of twy/twy mice was significantly lower than that of ICR mice. The inflammatory response has been identified in the chronic compression of cervical spinal cord. Microglia/macrophages polarization may participate in the inflammatory response, causing neuron apoptosis and limb dysfunction. These results are consistent with the Hirai's report (17), despite the mechanism of the microglia/ macrophages polarization remains unknown.

\section{MK2 signaling pathway may be involved in the regulation of microglia/macrophages polarization}

The inflammatory response is one of the important pathological processes in the compression injury of spinal cord. Microglia/macrophages are important inflammatory cells with the injury $(12,14)$. The proportion of M1 and
M2 microglia/macrophages in different pathological stages determines the prognosis of the injury. The polarization of cells from M1 to M2 is beneficial to the recovery of spinal cord functions (17). Therefore, the study on the signaling pathway regulation of microglia polarization is meaningful to both the intervention of microglia transformation between M1 and M2, and the treatment of the inflammatory injury of spinal cord compression. The present work as well as the literatures suggest that M1 and M2 cells be polarized in the chronic compression injury of spinal cord. However, it is not clear how this polarization can be regulated.

Microglia/macrophages polarization is a complex process of multifactor interactions. It can be regulated by a variety of intracellular signaling molecules and their pathways (18). Up to now most studies dealt with the signaling pathways of macrophages polarization regulation in non-nerve tissue (19). In the metabolic response to obesity, the C-Jun $\mathrm{N}$-terminal kinase (JNK) signaling pathway regulates the macrophage polarization to M1 type, which leads to insulin resistance (20). In liver cancer cells, B7-H3 protein induce M2-type polarization of TAMs through B7-H3/STAT3 signaling pathway and participates in the development of liver cancer (21). However, there are only a few reports concerning the regulation of microglia polarization in neural tissue, especially for the compression injury of spinal cord. The inflammatory response due to this injury is complicated and involves numerous cellular molecules and signaling pathways, such as the p38a mitogen-activated protein kinase (MAPK) pathway (22). The key downstream kinase, MK2 may regulate inflammation. Our previous research indicated that the MK2 signaling pathway was involved in neuro-inflammation of the chronic compressive injury of cervical spinal cord. Blocking the MK2 signaling pathway can reduce the inflammatory response (2). However, whether MK2 signaling pathway can regulate the microglia polarization or not requires further investigations.

In this study, microglia/macrophages polarization was identified in the chronic compression of cervical spinal cord for twy/twy mice. Applying the MK2 blocker PF-3644022, MK2 and the inflammatory cytokines (TNF- $\alpha, N F-\kappa B$ and IL-1 $\beta$ ) in the spinal cord of twy/twy mice were significantly down regulated. The apoptosis related gene Bax was down regulated too. Bal-2 was up regulated remarkably. Meanwhile, the M2 cell was up regulated. The M1 cell was decreased. Western blot results showed that the expression of M2 cell was increased and that of M1 cell and MK2 were decreased. The BMS score indicated that the motor function of twy/twy mice treated with the MK2 blocker 
was improved as compared to that without MK2 blocker. These results showed that with blocking the MK2 signaling pathway, microglia/macrophages were transformed from M1 to M2 type. The inflammatory response of the chronic compression injury was decreased. It is suggested that MK2 may be involved in the regulation of microglia polarization in spinal cord. Blocking the MK2 signaling pathway is conducive to the microglia polarization to M2 phenotype, and therefore alleviating the inflammatory response of the chronic compression injury and promoting the recovery of spinal cord function.

\section{Conclusions}

Microglia/macrophages are involved in the inflammatory response of chronic compression in cervical spinal cord. The MK2 signaling pathway may promote the microglia polarization to the M1 phenotype, and aggravate the inflammatory response of the spinal cord injury. Blocking MK2 signaling pathway can enhance the microglia/ macrophages polarization from $M 1$ to $M 2$, thereby reducing the inflammatory response and promoting the recovery of spinal cord injury. Intervention of the conversion of microglia/macrophages between M1 and M2 through MK2 signaling pathway may be helpful to the treatment of the chronic compression injury of cervical spinal cord.

\section{Acknowledgments}

Funding: This study was supported by National Natural Science Foundation of China (No. 81470103).

\section{Footnote}

Reporting Checklist: The authors have completed the ARRIVE Reporting Checklist. Available at http://dx.doi. org/10.21037/apm-20-396

Data Sharing Statement: Available at http://dx.doi. org/10.21037/apm-20-396

Conflicts of Interest: All authors have completed the ICMJE uniform disclosure form (available at http://dx.doi. org/10.21037/apm-20-396). The authors have no conflicts of interest to declare.

Ethical Statement: The authors are accountable for all aspects of the work in ensuring that questions related to the accuracy or integrity of any part of the work are appropriately investigated and resolved. Experiments were performed under a project license (No. XWH201905001) granted by institutional ethics committee of Xuanwu Hospital, Capital Medical University, in compliance with Xuanwu Hospital, Capital Medical University institutional guidelines for the care and use of animals.

Open Access Statement: This is an Open Access article distributed in accordance with the Creative Commons Attribution-NonCommercial-NoDerivs 4.0 International License (CC BY-NC-ND 4.0), which permits the noncommercial replication and distribution of the article with the strict proviso that no changes or edits are made and the original work is properly cited (including links to both the formal publication through the relevant DOI and the license). See: https://creativecommons.org/licenses/by-nc-nd/4.0/.

\section{References}

1. Lebl DR, Bono CM. Update on the Diagnosis and Management of Cervical Spondylotic Myelopathy. J Am Acad Orthop Surg 2015;23:648-60.

2. Song H, Fang X, Wen M, et al. Role of MK2 signaling pathway in the chronic compression of cervical spinal cord. Am J Transl Res 2015;7:2355-63.

3. Wilson JR, Tetreault LA, Kim J, et al. State of the Art in Degenerative Cervical Myelopathy: An Update on Current Clinical Evidence. Neurosurgery 2017;80:S33-S45.

4. Beattie MS, Manley GT. Tight squeeze, slow burn: inflammation and the aetiology of cervical myelopathy. Brain 2011;134:1259-61.

5. Yu WR, Liu T, Kiehl TR, et al. Human neuropathological and animal model evidence supporting a role for Fasmediated apoptosis and inflammation in cervical spondylotic myelopathy. Brain 2011;134:1277-92.

6. Uchida K, Nakajima H, Watanabe S, et al. Apoptosis of neurons and oligodendrocytes in the spinal cord of spinal hyperostotic mouse (twy/twy): possible pathomechanism of human cervical compressive myelopathy. Eur Spine J 2012;21:490-7.

7. Inukai T, Uchida K, Nakajima H, et al. Tumor necrosis factor-alpha and its receptors contribute to apoptosis of oligodendrocytes in the spinal cord of spinal hyperostotic mouse (twy/twy) sustaining chronic mechanical compression. Spine (Phila Pa 1976) 2009;34:2848-57.

8. Mourey RJ, Burnette BL, Brustkern SJ, et al. A benzothiophene inhibitor of mitogen-activated protein 
kinase-activated protein kinase 2 inhibits tumor necrosis factor alpha production and has oral anti-inflammatory efficacy in acute and chronic models of inflammation. J Pharmacol Exp Ther 2010;333:797-807.

9. Basso DM, Fisher LC, Anderson AJ, et al. Basso Mouse Scale for locomotion detects differences in recovery after spinal cord injury in five common mouse strains. J Neurotrauma 2006;23:635-59.

10. Li Q, Dai Z, Cao Y, et al. Caspase-1 inhibition mediates neuroprotection in experimental stroke by polarizing M2 microglia/macrophage and suppressing NFkappaB activation. Biochem Biophys Res Commun 2019;513:479-85.

11. Chen C, Chu SF, Ai QD, et al. CKLF1 Aggravates Focal Cerebral Ischemia Injury at Early Stage Partly by Modulating Microglia/Macrophage Toward M1 Polarization Through CCR4. Cell Mol Neurobiol 2019;39:651-69.

12. Amo-Aparicio J, Martínez-Muriana A, Sánchez-Fernández A, et al. Neuroinflammation Quantification for Spinal Cord Injury. Curr Protoc Immunol 2018;123:e57.

13. Orihuela R, McPherson CA, Harry GJ. Microglial M1/ M2 polarization and metabolic states. Br J Pharmacol 2016;173:649-65.

14. Zeng Y, Wang N, Guo T, et al. Snx27 Deletion Promotes Recovery From Spinal Cord Injury by Neuroprotection and Reduces Macrophage/Microglia Proliferation. Front Neurol 2018;9:1059.

15. Yang Z, Kuboyama T, Tohda C. Naringenin promotes

Cite this article as: Yu L, Song $\mathrm{H}$, Fang X, Hu Y. Role of MK2 signaling pathway mediating microglia/macrophages polarization in chronic compression injury of cervical spinal cord. Ann Palliat Med 2021;10(2):1304-1312. doi: 10.21037/apm20-396 microglial M2 polarization and Abeta degradation enzyme expression. Phytother Res 2019;33:1114-21.

16. Kigerl KA, Gensel JC, Ankeny DP, et al. Identification of two distinct macrophage subsets with divergent effects causing either neurotoxicity or regeneration in the injured mouse spinal cord. J Neurosci 2009;29:13435-44.

17. Hirai T, Uchida K, Nakajima H, et al. The prevalence and phenotype of activated microglia/macrophages within the spinal cord of the hyperostotic mouse (twy/twy) changes in response to chronic progressive spinal cord compression: implications for human cervical compressive myelopathy. PLoS One 2013;8:e64528.

18. Yao A, Liu F, Chen K, et al. Programmed death 1 deficiency induces the polarization of macrophages/ microglia to the M1 phenotype after spinal cord injury in mice. Neurotherapeutics 2014;11:636-50.

19. Murray PJ. Macrophage Polarization. Annu Rev Physiol 2017;79:541-66.

20. Han MS, Jung DY, Morel C, et al. JNK expression by macrophages promotes obesity-induced insulin resistance and inflammation. Science 2013;339:218-22.

21. Kang FB, Wang L, Li D, et al. Hepatocellular carcinomas promote tumor-associated macrophage M2polarization via increased $\mathrm{B} 7-\mathrm{H} 3$ expression. Oncol Rep 2015;33:274-82.

22. Zhou D, Huang C, Lin Z, et al. Macrophage polarization and function with emphasis on the evolving roles of coordinated regulation of cellular signaling pathways. Cell Signal 2014;26:192-7. 